\title{
Downregulation of Long Non-Coding RNA Kcnq1ot1: An Important Mechanism of Arsenic Trioxide-Induced Long QT Syndrome
}

\author{
Yanan Jiang ${ }^{\mathrm{a}}$ Weijie Du ${ }^{\mathrm{a}}$ Qun Chu ${ }^{\mathrm{a}}$ Ying Qin ${ }^{\mathrm{b}}$ Gulnara Tuguzbaevab,c \\ Hui Wanga Anqi Lia Guiyang Lia Yanyao Lia Lu Chai ${ }^{a}$ Er Yue $^{\mathrm{a}} \mathrm{Xi}^{\mathrm{a}} \mathrm{Sun}^{\mathrm{a}}$ \\ Zhiguo Wang ${ }^{b}$ Valentin Pavlov ${ }^{c}$ Baofeng Yang ${ }^{a, b, d}$ Yunlong Bai ${ }^{a, b}$ \\ aDepartment of Pharmacology (State-Province Key Laboratories of Biomedicine- Pharmaceutics \\ of China, Key Laboratory of Cardiovascular Research, Ministry of Education), College of Pharmacy, \\ Harbin Medical University, Harbin; ${ }^{\mathrm{b}}$ Translational Medicine Research and Cooperation Center of \\ Northern China, Heilongjiang Academy of Medical Sciences, Harbin, China; 'Central laboratory of \\ scientific research, Bashkir State Medical University, Ufa, Republic Bashkortostan, Russian Federation; \\ dDepartment of Pharmacology and Therapeutics, Melbourne School of Biomedical Sciences, Faculty of \\ Medicine, Dentistry and Health Sciences, University of Melbourne, Melbourne, Australia
}

\section{Key Words}

Arsenic trioxide $\bullet$ Long QT syndrome $\bullet$ LncRNA Kcnq1ot1 $・$ Kcnq1

\begin{abstract}
Background/Aims: Arsenic trioxide (ATO) is a known anti-acute promyelocytic leukemia $(\mathrm{APL})$ reagent, whose clinical applications are limited by its serious cardiac toxicity and fatal adverse effects, such as sudden cardiac death resulting from long QT syndrome (LQTS). The mechanisms of cardiac arrhythmia due to ATO exposure still need to be elucidated. Long non-coding RNAs (IncRNAs) are emerging as major regulators of various pathophysiological processes. This study aimed to explore the involvement of IncRNAs in ATO-induced LQTS in vivo and in vitro. Methods: For in vivo experiments, mice were administered ATO through the tail vein. For in vitro experiments, ATO was added to the culture medium of primary cultured neonatal mouse cardiomyocytes. To evaluate the effect of IncRNA Kcnq1ot1, siRNA and lentivirus-shRNA were synthesized to knockdown IncRNA Kcnqlot1. Results: After ATO treatment, the Kcnq1ot1 and Kcnq1 expression levels were down regulated. IncRNA Kcnq1ot1 knockdown prolonged the action potential duration (APD) in vitro and exerted LQTS in vivo. Correspondingly, Kcnq1 expression was decreased after silencing IncRNA Kcnq1ot1. However, the knockdown of Kcnq1 exerted no effect on IncRNA Kcnq1ot1 expression. Conclusions: To our knowledge, this report is the first to demonstrate that IncRNA Kcnq1ot1 downregulation is responsible for QT interval prolongation induced by ATO at least partially by repressing Kcnq1 expression. IncRNA Kcnq1ot1 has important pathophysiological functions in the heart and could become a novel antiarrhythmic target.

Y. Jiang, W. Du and Q. Chu contributed equally to this work.




\section{Cellular Physiology Cell Physiol Biochem 2018;45:192-202 \begin{tabular}{ll|l} 
and Biochemistry Published online: January 15, 2018 & $\begin{array}{l}\text { (c) } 2018 \text { The Author(s). Published by S. Karger AG, Basel } \\
\text { www.karger.com/cpb }\end{array}$
\end{tabular}}

Jiang et al.: : Lncrna Kcnq1ot1 is Involved in the Generation of LQTS

\section{Introduction}

Arsenic trioxide (ATO) is a well-known traditional medicine with the chemical formula $\mathrm{As}_{2} \mathrm{O}_{3}$. In the 1970s, Dr. Zhang Tingdong, a Chinese researcher, uncovered the extraordinary therapeutic potential of ATO against acute promyelocytic leukemia (APL). Since then, ATO (Trisenox ${ }^{\mathrm{TM}}$ ) has become a choice for the treatment of relapsed or refractory APL worldwide. Thus far, it is the most active and effective single agent in the treatment of APL. ATO-based salvage therapy offers long-lasting remissions and cures up to $90 \%$ of patients with relapsed APL [1-3].

However, the high frequency and severity of complex arrhythmias as a consequence of the compound's cardiotoxicity limited the clinical application of ATO. Long QT syndrome (LQTS) is the most common cardiac rhythm abnormality observed during ATO therapy [3, 4]. Approximately, two thirds of patients receiving ATO develop significant but rapidly reversible QTc prolongation, which can predispose patients to temporary discontinuation, torsade de pointes and even sudden cardiac death unless stringent precautions are taken [5]. Due to these adverse cardiac effects, some patients have to be precluded from ATO therapy for APL. Therefore, clarifying the molecular toxicity mechanisms of ATO and minimizing the risk of LQTS are very important.

LQTS is characterized by delayed cardiac repolarization and increased risk of developing potentially fatal ventricular arrhythmias. It can be divided into congenital and acquired LQTS. Congenital LQTS is identified as LQT1 to LQT13 according to mutations in different genes [6, 7]. KCNQ1/KCNE1-encoded slow delayed rectifying $\mathrm{K}^{+}$channel $\left(\mathrm{I}_{\mathrm{KS}}\right)$ are expressed in diverse tissues and serve a variety of functions [8-10]. Mutation of KCNQ1 is a cause of LQT1, making up approximately $40 \%$ to $55 \%$ of all LQTS cases [11]. In addition, Kcnq1-deficient mice show an LQTS phenotype [12]. $\mathrm{I}_{\mathrm{Ks}}$ blockade significantly contributes to acquired LQTS, especially when repolarization reserve is reduced [13]. Most studies have shown that the QT prolongation induced by ATO can be attributed to cardiac repolarization abnormalities [14]. The chaos of ion channel stability has been well characterized in ATO-related cardiotoxicity. The alteration of Kcnq1 is involved in ATO-induced QT interval prolongation [14]. However, the regulatory mechanisms for this involvement are still not fully understood.

Long non-coding RNAs (lncRNAs) are functional RNA molecules larger than 200 nucleotides without protein-coding potential. Recently, increasing evidence has suggested that IncRNAs play important roles in cardiac development and diseases, including acute myocardial infarction, hypertrophy and heart failure [15-18]. KCNQ1 overlapping transcript1 (Kcnq1ot1) is an lncRNA transcribed from the KCNQ1 locus. It plays pivotal regulatory role in the expression of both ubiquitously and tissue-specific imprinted genes within the Kcnq1 domain and is thus involved in the pathogenesis of cancer, acute myocardial infarction and Beckwith-Wiedemann syndrome [19-22]. Therefore, it is likely that alteration of the lncRNA Kcnq1ot1 may affect cardiac rhythm through the regulation of Kcnq1.

In preliminary experiments, we found that ATO inhibited the expression of both Kcnq1ot1 and Kcnq1 in primary cultured neonatal mouse cardiomyocytes. In addition, AT0-induced LQTS was associated with the blockage of $\mathrm{I}_{\mathrm{KS}}$ [14]. Based on these findings, we hypothesized that the alteration of IncRNA Kcnq1ot1 may be an important mechanism of ATO-induced LQTS.

\section{Materials and Methods}

\section{Animals}

Mice were obtained from the Experimental Animal Center of Harbin Medical University. The methods were performed in accordance with the National Guidelines for Experimental Animal Welfare (the Ministry of Science and Technology, People's Republic of China, 2006) and the Guide for the Care and Use of Laboratory Animals published by the US National Institutes of Health (NIH Publication No. 85-23, revised 1996). All experimental protocols were pre-approved by the Experimental Animal Ethic Committee of Harbin Medical University, China (No. HMUIRB 20150034). 


\section{Cellular Physiology Cell Physiol Biochem 2018;45:192-202 \begin{tabular}{l|l} 
and Biochemistry Published online: January 15, 2018 & $\begin{array}{l}\text { C } 2018 \text { The Author(s). Published by S. Karger AG, Basel } \\
\text { www.karger.com/cpb }\end{array}$
\end{tabular}}

Jiang et al.: : Lncrna Kcnq1ot1 is Involved in the Generation of LQTS

\section{Isolation and culture of neonatal mouse cardiomyocytes}

One- to three-day-old neonatal mice were rinsed quickly in $75 \%$ ethanol solution for surface sterilization. Hearts were extracted from the body and were transferred immediately into the bacterial dish containing cold DMEM (HyClone, UT, USA). The ventricles were washed and minced into small pieces. The cells were dissociated at $37^{\circ} \mathrm{C}$ with trypsin-EDTA solution (Beyotime Institute of Biotechnology, Jiangsu, China). Cells from subsequent digestion were added to an equal volume of DMEM containing $10 \%$ fetal bovine serum (BI, Kibbutz Beit Haemek, Israel) and were kept at $4^{\circ} \mathrm{C}$. After final collection, the resulting mixture was filtered and centrifuged for $3 \mathrm{~min}$ at $1500 \mathrm{rpm}$ to obtain pellet cells. The cells were resuspended in culture medium and incubated for $1.5 \mathrm{~h}$ under a water-saturated atmosphere of $5 \% \mathrm{CO}_{2}-95 \%$ air to allow the attachment of non-cardiomyocytes. The suspended cells were then collected, plated into a new culture plate and incubated under the same conditions as mentioned above.

In vitro and in vivo model of ATO-induced cardiotoxicity

Neonatal mouse cardiomyocytes were incubated with or without ATO (2.5 or $5 \mu \mathrm{M})$ for $48 \mathrm{~h}$. Subsequently, the total RNA and protein were extracted for the following experiments. Male adult Kunming mice weighting 25-30 g were used in this experiment. ATO $\left(0.5,1.5\right.$ or $\left.4.5 \mathrm{mg} \cdot \mathrm{kg}^{-1}\right)$ or an equivalent volume of saline was administered to mice through the tail vein on alternate days. The electrocardiograms (ECGs) were monitored before and 7 days after treatment. The cardiac tissues were collected and frozen at $-80^{\circ} \mathrm{C}$ until further analysis.

\section{siRNA transfection}

Neonatal mouse cardiomyocytes were transfected with siRNA targeting Kcnq1ot1 or scrambled negative control siRNA (GenePharma, Shanghai, China) using X-treme GENE siRNA transfection reagent (Roche Applied Science, Prague, Czech Republic) according to the manufacturer's instructions. The siRNA sequences were as follows: si-Kcnq1ot1-1, GGGAAUCUGGUCUAAUGAATT, UUCAUUAGACCAGAUUCCCTT; siKcnq1ot1-2, CCUGGUGAAGGUACUAAAUTT, AUUUAGUACCUUCACCAGGTT.

\section{Lentivirus-shRNA transfection}

Lentivirus-shRNAs were designed and synthesized by GenePharma (GenePharma, Shanghai, China). Initially, the effects of lentivirus-shRNA were verified in vitro. Lentivirus-shRNAs were added to culture medium to yield a final multiplicity of infection (MOI) of 1 . For in vivo experiments, lentivirus-shRNA $\left(1 \times 10^{9}\right.$ TU) diluted in $50 \mu \mathrm{L}$ of saline was administered to mice through the tail vein.

\section{Whole-cell patch clamp recording}

Action potential duration (APD) was measured by the whole-cell patch-clamp method using a MultiClamp 700B amplifier (Axon Instruments, CA, USA). All experiments were performed using pCLAMP 10.2 software (Axon Instruments, Foster City, CA, USA). Boltzman's fits were performed.

\section{Electrocardiograms}

The standard limb lead II ECG was continuously recorded using a BL420s multichannel recorder (TME Technology, Chengdu, China). Arrythmias in mouse hearts were measured by ECG for a continuous period of $10 \mathrm{~min}$. The rate-corrected QT interval (QTc) was calculated using Bazett's formula: QTc $=\mathrm{QT} /(\mathrm{RR} / 100)^{1 / 2}$ [23].

\section{Real-time reverse transcriptase polymerase chain reaction (RT-PCR)}

Total RNA was extracted using TRIzol reagent (Invitrogen, CA, USA) from neonatal mouse cardiomyocytes or mouse myocardium. First-strand cDNA was synthesized using a reverse transcriptase kit (TaKaRa, Shiga, Japan) according to the manufacturer's instructions. Real-time RT-PCR analysis was performed on an ABI 7500 fast Real Time PCR system (Applied Biosystems, CA, USA) using SYBR Green I (Toyobo, Osaka, Japan). The thermal cycling conditions consisted of one cycle for $60 \mathrm{~s}$ at $95^{\circ} \mathrm{C}$ and 40 cycles of $15 \mathrm{~s}$ at $95^{\circ} \mathrm{C}$, $15 \mathrm{~s}$ at $60^{\circ} \mathrm{C}$ and $45 \mathrm{~s}$ at $72^{\circ} \mathrm{C}$. GAPDH served as an internal control. Relative expression levels of target genes were calculated using the $2^{-\Delta \Delta C T}$ method. The primers sequences were as follows: Gapdh, 5'-AAGAAGGTGGTGAAGCAGGC-3' (forward), 5'-TCCACCACCCTGTTGCTGTA-3' (reverse); Kcnq1ot1, 5'-GCACTCTGGGTCCTGTTCTC-3' (forward) 5'-CACTTCCCTGCCTCCTACAC-3' (reverse); Kcnq1, 5'-CAAAGACCGTGGCAGTAAC-3' (forward), 5'-CCTTCATTGCTGGCTACAAC-3' (reverse); Kcnh2, 5'-TGGGGAGAAAAGTGACACCTG -3' (forward), 
5'-CAGGGCTAGACAAGGGGATG -3' (reverse); Kcne2, 5'-GGTCTCAAGCTGAAAGTGCC -3' (forward), 5'-TGCTGTGTGGTATGTGAGCA -3' (reverse).

\section{Western blot analysis}

Total protein extractions were obtained from neonatal mouse cardiomyocytes or cardiac tissues. The protein samples were separated by electrophoresis in $10 \%$ sodium dodecyl sulfate polyacrylamide gels, and the protein was transferred to polyvinylidene difluoride membranes (Millipore, MA, USA). Membranes were blocked with $5 \%$ non-fat dry milk in phosphate-buffered saline (PBS) for $2 \mathrm{~h}$. The blots were incubated overnight at $4^{\circ} \mathrm{C}$ with primary antibodies. The next day, membranes were washed three times for 10 min each time with PBS containing $0.5 \%$ Tween 20 (PBS-T) and were then incubated with secondary antibodies for $1 \mathrm{~h}$ at room temperature. Finally, membranes were rinsed with PBS before scanning. Images were captured on the GelDox XR System (Bio-Rad, CA, USA). Western blotting bands were quantified using Quantity one software. Gapdh served as an internal control.

\section{Data analysis}

Data are expressed as the means \pm SEM and were analyzed with SPSS 13.0 software. Statistical comparisons between two groups were performed using Student's t-test. Statistical comparisons among multiple groups were examined using analysis of variance (ANOVA). A two-tailed $P<0.05$ was considered statistically significant. Graphs were generated using GraphPad Prism 5.0.

\section{Results}

QTc interval is prolonged in mice treated with ATO

To evaluate the effect of ATO on QTc interval, mice were administered different doses of ATO. No significant difference was observed between the $0.5 \mathrm{mg} \cdot \mathrm{kg}^{-1}$ group and the control group after 7 days of treatment. However, the QTc interval was prolonged in the 1.5 and 4.5 $\mathrm{mg} \cdot \mathrm{kg}^{-1}$ groups compared with the control group (Fig. 1).

\section{ATO downregulates Kcnq1 and IncRNA Kcnq1ot1 expression both in vivo and in vitro}

The cardiac tissues were harvested after ECG recording in mice. The expression levels of lncRNA Kcnq1ot1 and Kcnq1 were determined using real-time PCR and western blot analysis. ATO at the doses of 1.5 and $4.5 \mathrm{mg} \cdot \mathrm{kg}^{-1}$ significantly decreased Kcnq1ot1 expression (Fig. 2A). Meanwhile, the Kcnq1 mRNA and protein expression levels were both downregulated (Fig. 2B \& C). Similarly, Kcnq1ot1 and Kcnq1 expression levels were also downregulated in neonatal mouse cardiomyocytes incubated with ATO (Fig. 2D-F).

siRNA targeting IncRNA Kcnq1ot1 downregulates Kcnq1 expression in cardiomyocytes

To assess the effect of lncRNA Kcnq1ot1 knockdown on Kcnq1 expression, two different siRNAs were used. IncRNA Kcnq1ot1 expression was significantly downregulated after transfection in neonatal mouse cardiomyocytes. Both of the siRNAs targeting lncRNA

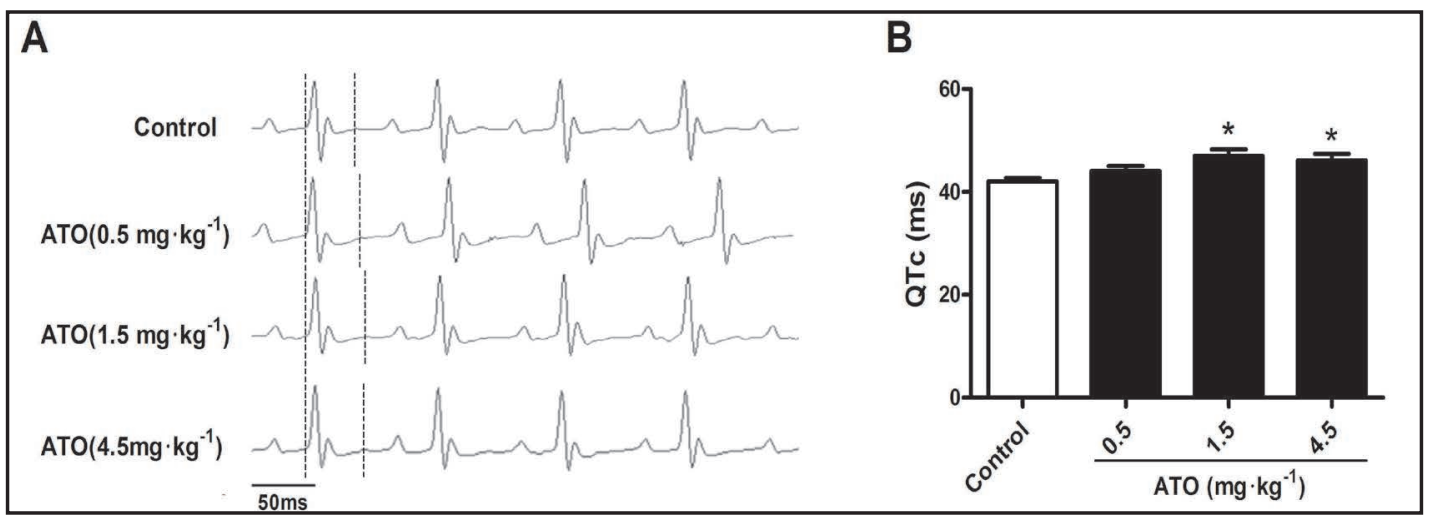

Fig. 1. Prolongation of corrected QT (QTc) in mice treated with arsenic trioxide (ATO). (A) Representative electrocardiogram. (B) ATO treatment prolonged QTc in mice. ${ }^{*} \mathrm{P}<0.05$ versus Control; $\mathrm{n}=6$. 


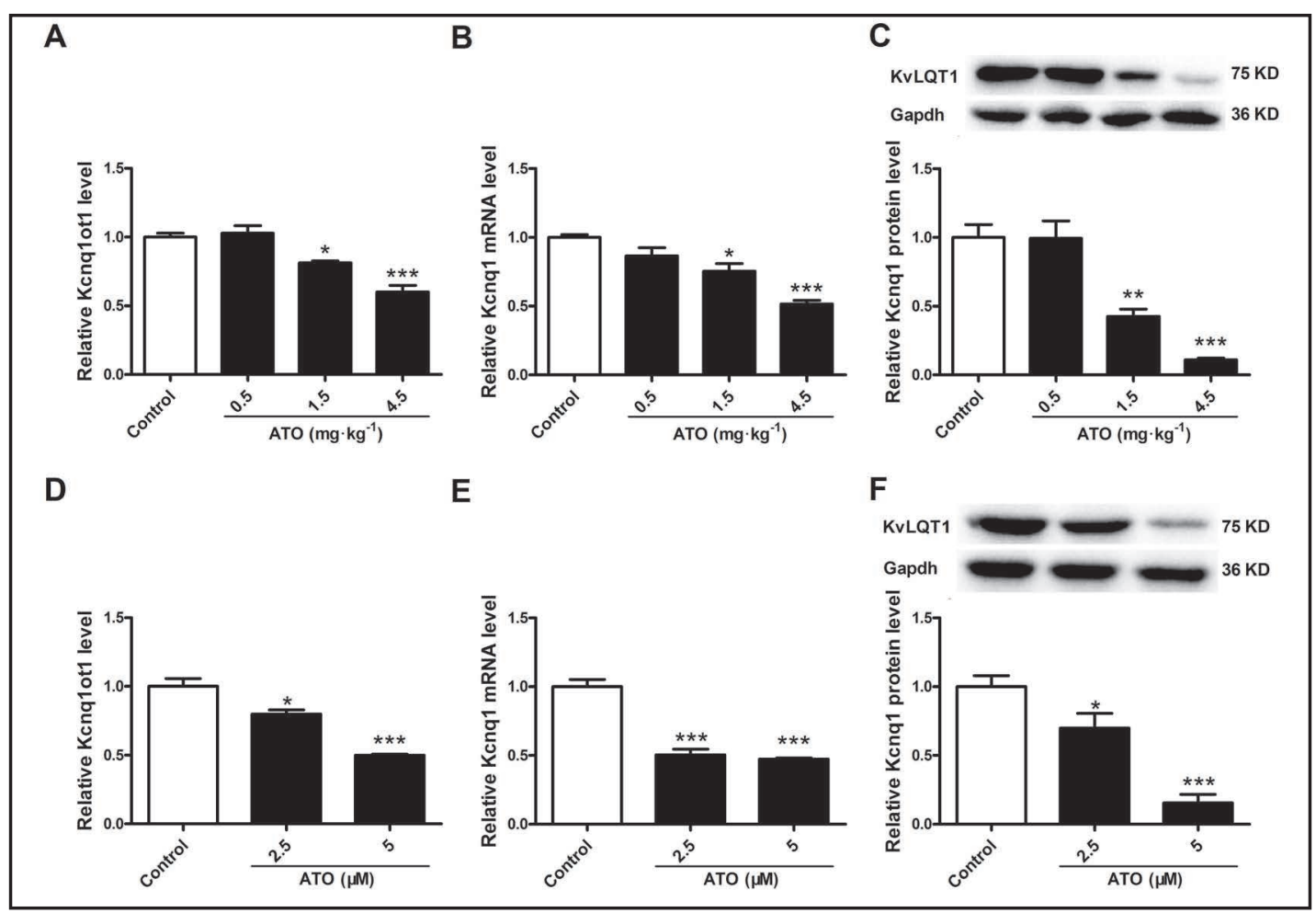

Fig. 2. Expression downregulation of IncRNA Kcnq1ot1 and Kcnq1 by arsenic trioxide (ATO) in vivo and in vitro. IncRNA Kcnq1ot1 (A), Kcnq1 mRNA (B) and KvLQT1 (C) expression in the myocardium of ATO-treated mice. IncRNA Kcnq1ot1 (D), Kcnq1 mRNA (E) and KvLQT1 (F) expression in ATO-treated neonatal mouse cardiomyocytes. ${ }^{*} \mathrm{P}<0.05$ versus Control, ${ }^{* *} \mathrm{P}<0.01$ versus Control, ${ }^{* * *} \mathrm{P}<0.001$ versus Control; $\mathrm{n}=3$.

Kcnq1ot 1 exerted similar effects on Kcnq1 expression. The mRNA and protein expression levels of Kcnq1 were both downregulated after the silencing of Kcnq1ot1 (Fig. 3). The siRNA with better efficiency was selected for the subsequent experiments.

\section{IncRNA Kcnq1ot1 knockdown lengthens APD in cardiomyocytes}

APD in cardiac cells is the major determinant of the length of the QT interval. APD is governed by the balance between membrane depolarization and repolarization. The delayed rectifier $\mathrm{K}^{+}$current carried by the $\mathrm{I}_{\mathrm{Ks}}$ channel is responsible for the terminal phase of cardiac repolarization, and the latter is encoded by Kcnq1, which is regulated by Kcnq1ot1. Our results showed that after Kcnq1ot1 knockdown, the APD was significantly prolonged in primary cultured neonatal mouse cardiomyocytes (Fig. 4A \& B). However, Kcnh2 and Kcne2 mRNA expression levels were not changed (Fig. 4C \& D).

Lentivirus-shRNA targeting IncRNA Kcnq1ot1 decreases Kcnq1 expression in cardiomyocytes

The lentivirus carrying shRNA targeting lncRNA Kcnq1ot1 was constructed based on the siRNA sequence. After incubation with the lentivirus-shRNA, Kcnq1ot1 expression was significantly downregulated in neonatal mouse cardiomyocytes. Meanwhile, Kcnq1 mRNA and protein expression levels were also inhibited (Fig. 5).

\section{IncRNA Kcnq1ot1 knockdown exhibits a long QT phenotype in mice}

To determine whether IncRNA Kcnq1ot1 plays a role in cardiac repolarization, ECG recordings from Kcnq1ot1 knockdown and negative control mice were evaluated. The lentivirus-shRNA or the negative control shRNA was administered to mice through the tail vein. The QTc interval was prolonged from day 7 after Kcnq1ot1 knockdown (Fig. 6).

\section{KARGER}




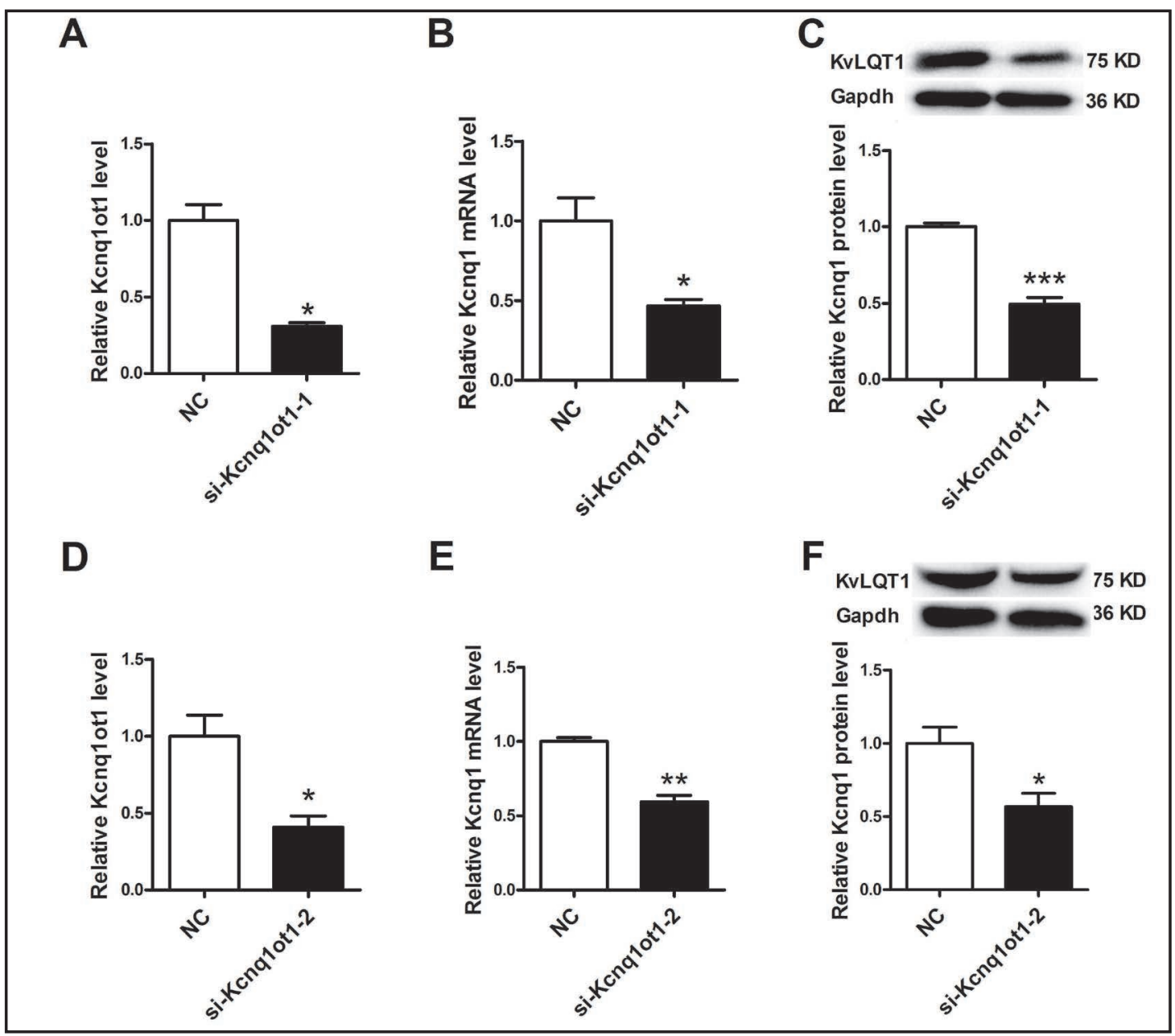

Fig. 3. Downregulation of Kcnq1 upon knockdown of endogenous Kcnq1ot1 by siRNA in neonatal mouse cardiomyocytes. si-Kcnq1ot1-1 and si-Kcnq1ot1-2 were used to knockdown lncRNA Kcnq1ot1. IncRNA Kcnq1ot1 (A \& D) and Kcnq1 mRNA (B \& E) expression levels were decreased. The expression of KvLQT1 (C $\&$ F) expression was also decreased. Gapdh served as an internal control. ${ }^{*} \mathrm{P}<0.05$ versus Control, ${ }^{* *} \mathrm{P}<0.01$ versus Control, ${ }^{* * *} \mathrm{P}<0.001$ versus Control; $\mathrm{n}=3$.

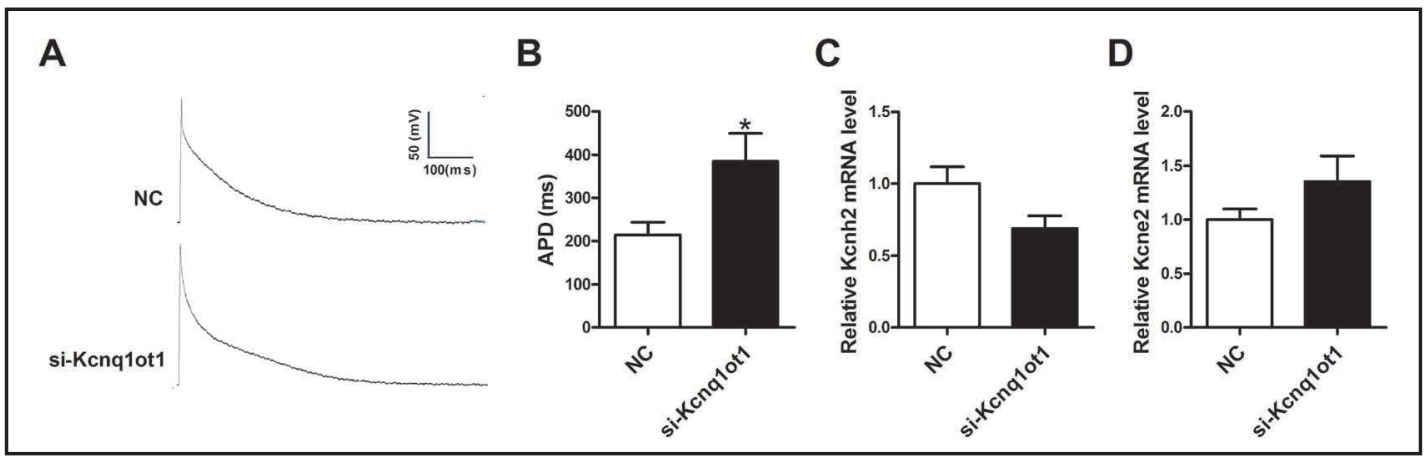

Fig. 4. Prolongation of action potential duration (APD) upon knockdown of endogenous Kcnq1ot1 by siRNA in neonatal mouse cardiomyocytes. (A) Representative cardiomyocyte action potential waveforms. (B) Action potential duration was prolonged after Kcnq1ot1 knockdown. (C) Kcnh2 mRNA expression was not changed after Kcnq1ot1 knockdown. (D) Kcne2 mRNA expression was not changed after Kcnq1ot1 knockdown. Gapdh served as an internal control. ${ }^{*} \mathrm{P}<0.05$ versus NC. $\mathrm{n}=4-5$. 
A

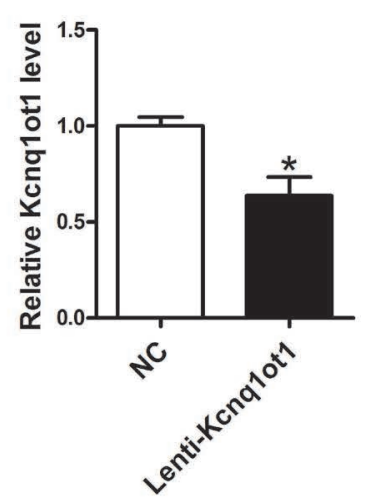

B

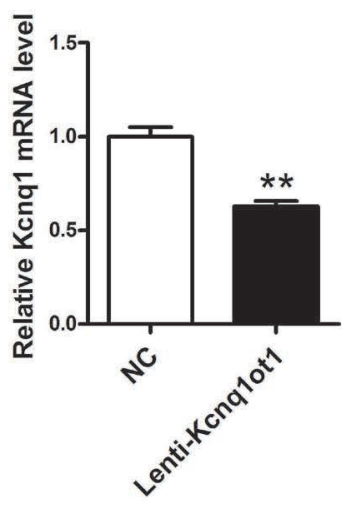

C
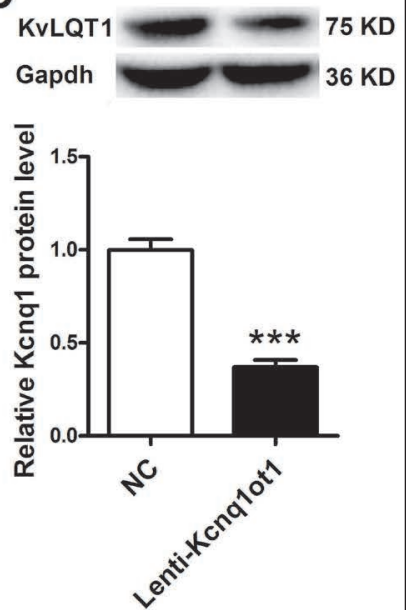

Fig. 5. Downregulation of Kcnq1 upon knockdown of endogenous Kcnq1ot1 by a lentivirus carrying shRNA in neonatal mouse cardiomyocytes. IncRNA Kcnq1ot1(A) and Kcnq1 mRNA (B) expression levels were decreased. KvLQT1 expression was also decreased. Gapdh served as an internal control. ${ }^{*} \mathrm{P}<0.05$ versus NC, ${ }^{* *} \mathrm{P}<0.01$ versus $\mathrm{NC},{ }^{* * *} \mathrm{P}<0.001$ versus Control; $\mathrm{n}=3$.

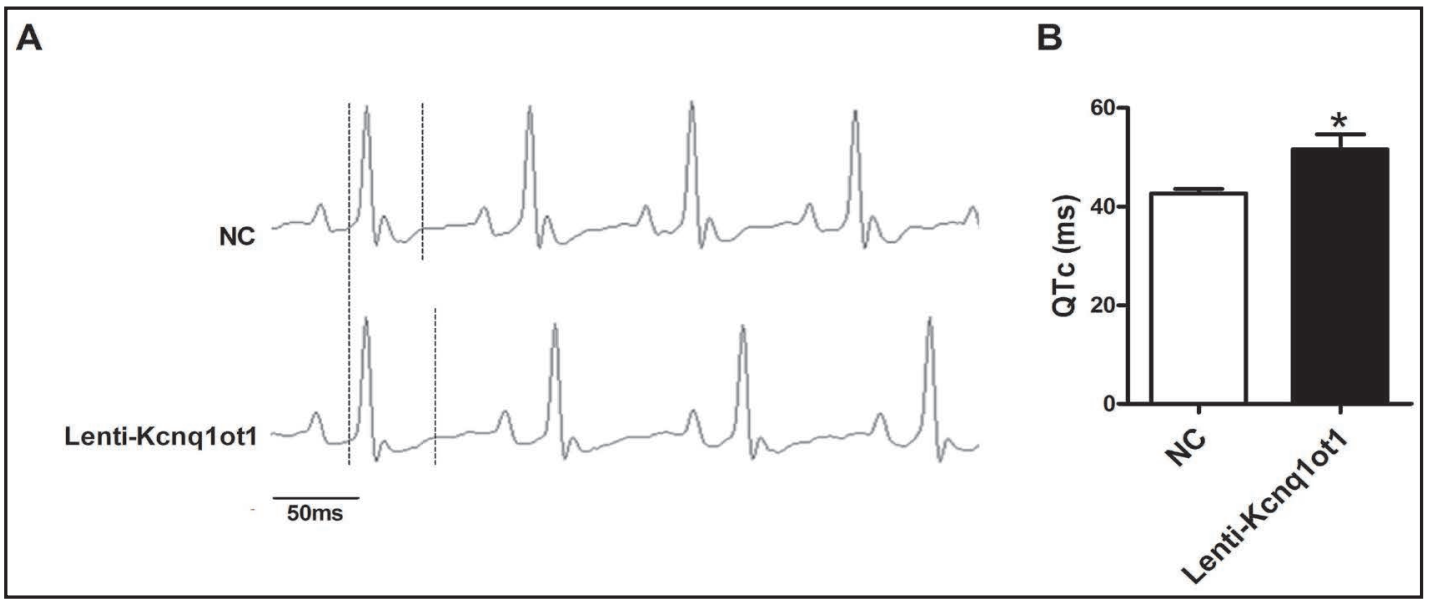

Fig. 6. Prolongation of corrected QT (QTc) upon knockdown of Kcnq1ot1 by lentivirus-shRNA in mice. (A) Representative electrocardiogram. (B) lncRNA Kcnq1 ot1 knockdown prolonged QTc in mice. ${ }^{*} \mathrm{P}<0.05$ versus $\mathrm{NC} ; \mathrm{n}=5$.

\section{Kcnq1ot1 knockdown decreases Kcnq1 expression in mice}

To determine the effects of IncRNA Kcnq1ot1 on Kcnq1 expression in vivo, cardiac tissues were harvested 7 days after administration of the lentivirus-shRNA. In accordance with in vitro experiments, IncRNA Kcnq1ot1 expression was downregulated. Meanwhile, Kcnq1 mRNA and protein expression levels were also decreased (Fig. 7A-C). However, downregulation of Kcnq1 exerted no effect on IncRNA Kcnq1ot1 expression (Fig. 7D-F).

\section{Discussion}

ATO is a highly effective treatment for APL. However, it can cause sudden cardiac death due to LQTS. Although dozens of studies have proposed several possible mechanisms, including disturbance of ion channel balance, apoptosis stimulation and promotion of oxidative injury, the exact regulatory network of ATO-induced cardiac toxicity has not been fully clarified [24-26].

\section{KARGER}




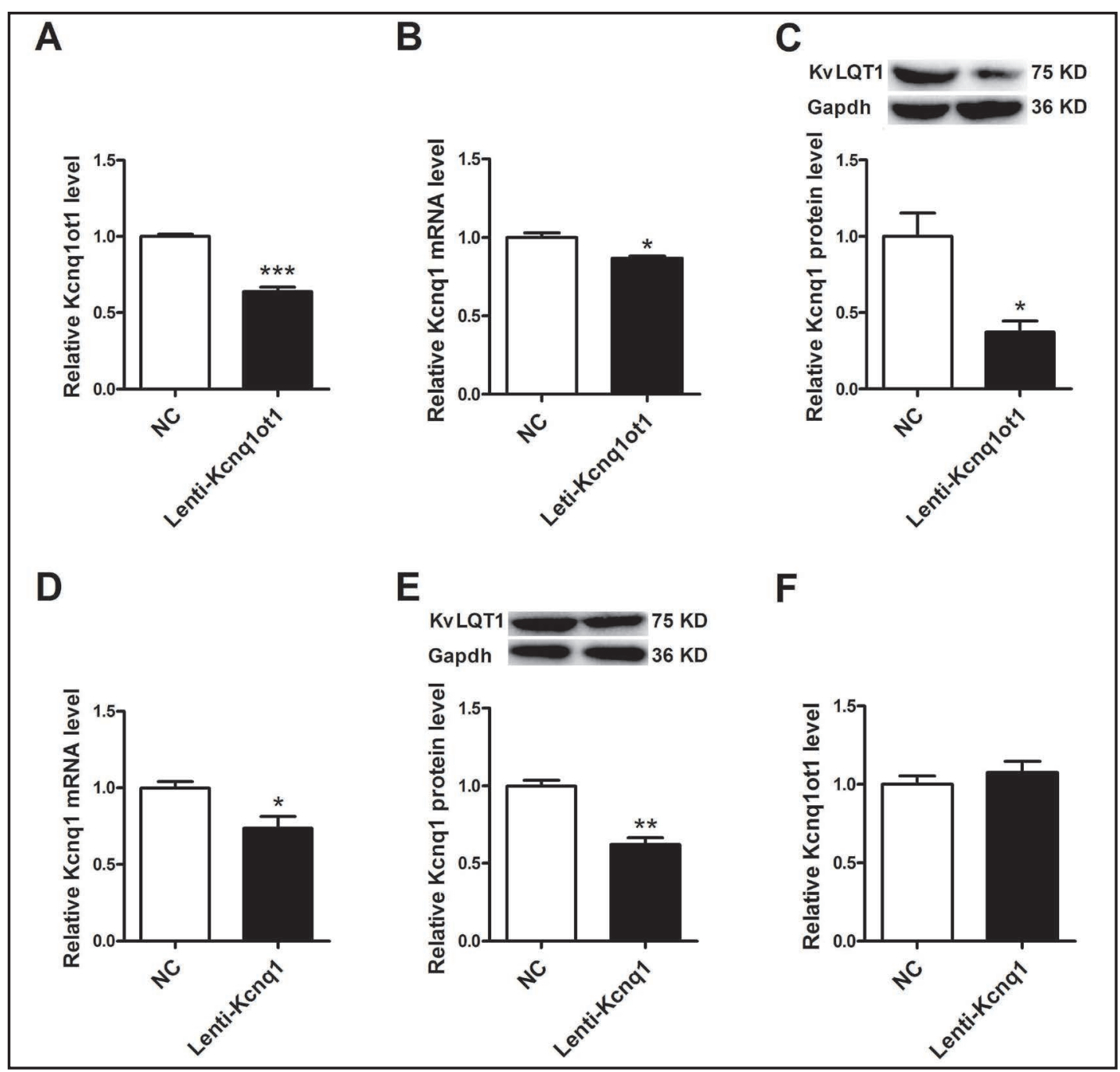

Fig. 7. Expression downregulation of Kcnq1 upon knockdown of Kcnq1ot1 by lentivirus-shRNA in mice. lncRNA Kcnq1ot1 (A), Kcnq1 mRNA (B) and KvLQT1 (C) expression levels were decreased in the myocardium of lenti-Kcnq1ot1-treated mice. Kcnq1 mRNA (D) and KvLQT1 (E) expression levels were decreased with no significant alteration of lncRNA Kcnq1ot1 (F) in the myocardium of lenti-Kcnq1ot1-treated mice. Gapdh served as an internal control. ${ }^{*} \mathrm{P}<0.05$ versus $\mathrm{NC},{ }^{* *} \mathrm{P}<0.01$ versus $\mathrm{NC},{ }^{* * *} \mathrm{P}<0.001$ versus $\mathrm{NC} ; \mathrm{n}=3-8$.

ATO at a median dose of $0.15 \mathrm{mg} \cdot \mathrm{kg}^{-1} \cdot \mathrm{d}^{-1}$, ranging from 0.06 to $0.2 \mathrm{mg} \cdot \mathrm{kg}^{-1} \cdot \mathrm{d}^{-1}$, is recommended for the clinical treatment of APL. The QT changes that occur are usually observed within 7 days after treatment [5]. To mimic clinical drug administration, mice were treated with ATO at dose of $0.5,1.5$ or $4.5 \mathrm{mg} \cdot \mathrm{kg}^{-1}$, with the median dose of ATO in mice being equal to that in humans. The ECGs of mice were then monitored during the experiment. Seven days after treatment, the QTc was prolonged in mice treated with median and high dose of ATO (Fig. 1). This result was in accordance with the research exploring the effect of ATO on QTC interval prolongation in mice [27]. Based on this model, we explored the molecular mechanisms of ATO-induced LQTS.

IncRNAs constitute a novel class of non-coding RNAs that regulate gene expression. Although there is a growing interest in lncRNA-mediated biological and pathophysiological functions, little is known about the involvement of lncRNAs in the regulation of cardiac rhythm. Kcnq1ot1 is a ubiquitously expressed lncRNA that is considered to have regulatory effects on cardiac development and is aberrantly expressed in the setting of myocardial ischemia $[28,29]$. To explore the molecular mechanisms of ATO-induced LQTS, we focused 
on Kcnq1ot1. Our results showed that ATO inhibited the expression of Kcnq1ot1 both in vitro and in vivo (Fig. 2A \& D). Moreover, Kcnq1 expression was also downregulated (Fig. 2B, C, E $\& \mathrm{~F})$.

To investigate the effects of IncRNA Kcnq1ot1 on Kcnq1, siRNAs targeting lncRNA Kcnq1ot1 were synthesized to knock down Kcnq1ot1 in neonatal mouse cardiomyocytes. Both of the siRNAs could efficiently and specifically down regulate Kcnq1ot1 expression, resulting in significant inhibition of Kcnq1(Fig. 3), and the APD was prolonged due to lncRNA Kcnq1ot1 knockdown (Fig. 4A \& B). Although $\mathrm{I}_{\mathrm{Kr}}$ is also considered as an important regulator in LQTS pathogenesis, IncRNA Kcnq1ot1 knockdown exerts no significant effects on the mRNA expression of Kcnh2 and Kcne2, which encode $\mathrm{I}_{\mathrm{Kr}}$ (Fig. 4C \& D).

To further detect the effect of lncRNA Kcnq1ot1 knockdown in vivo, lentivirusshRNA targeting lncRNA Kcnq1ot1 was constructed. The effects of lentivirus-shRNA were verified in vitro. After transfection, Kcnq1ot1 expression was inhibited in neonatal mouse cardiomyocytes (Fig. 5A). Meanwhile, Kcnq1 mRNA and protein expression levels were also decreased (Fig. 5B \& C). We then performed an in vivo experiment. The mice treated with lentivirus-shRNA targeting lncRNA Kcnq1ot1 exhibited a long QT phenotype in 7 days after lentivirus-shRNA administration (Fig. 6). In addition, Kcnq1 expression was also inhibited. These observations indicate that lncRNA Kcnq1ot1 knockdown could inhibit Kcnq1 expression (Fig. 7A-C). These results disagreed with the research conducted by Korostowski et al., who purposed that the absence of Kcnq1ot1 leads to Kcnq1 overexpression [29]. This discrepancy could be explained by the variability of IncRNA effects depending on development stage and pathologic status. We also investigated whether a positive feedback loop existed between IncRNA Kcnq1ot1 and Kcnq1 by knocking down Kcnq1 to observe the changes in lncRNA Kcnq1ot1 in vivo. Silencing of Kcnq1 exerted no significant effect on lncRNA Kcnq1ot1 (Fig. 7D-F). These findings indicated that ATO-induced LQTS was at least partially mediated by the regulation of the lncRNA Kcnq1ot1/Kcnq1 axis.

Theoretically, a rescue experiment aiming to observe whether Kcnq1ot1 upregulation could attenuate ATO-induced LQTS is indispensable. Unfortunately, due to technical difficulties, IncRNA Kcnq1ot1 overexpression could not be achieved. Therefore, RNA interference was performed to mimic the effect of ATO on Kcnq1ot1 in cardiomyocytes. Considering the characteristics of IncRNAs, it was difficult to proceed from mouse to human. Compared with protein-coding sequences, most lncRNAs are poorly conserved among vertebrates [30]. A recent study identified only 18 conserved lncRNAs in humans from 3133 mouse lncRNAs, confirming the fact that only a small minority of lncRNAs in mice or humans have transcribed homologous sequences across different species [31, 32]. In contrast, highly conserved lncRNAs could play critical and conserved roles across different species [33]. Fortunately, Kcnq1ot1 is a relatively conserved lncRNA and likely exerts similar effects in different species. For instance, the dysfunction of Kcnq1ot1 is responsible to BeckwithWiedemann syndrome in humans, similar to what has been observed for large offspring syndrome in bovines $[34,35]$. In the present study, we found that the aberrant expression of lncRNA Kcnq1ot1 was involved in ATO-induced LQTS in mice and could likely have a similar effect in humans. However, it remains to be further investigated whether homologous IncRNA KCNQ1OT1 is aberrantly expressed in APL patients treated with ATO or merely in those with LQTS.

Overall, this study is the first to demonstrate that lncRNAs have regulatory potential for cardiac rhythm. The discovery of IncRNA Kcnq1ot1-mediated effects on cardiac rhythm in ATO-induced LQTS not only proposes a therapeutic target for ameliorating the cardiac toxicity of ATO but also provides a novel strategy for the treatment of arrhythmias and other related diseases.

\section{Disclosure Statement}

The authors declare no conflicts of interest.

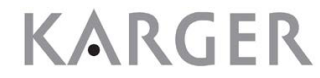




\section{Cellular Physiology

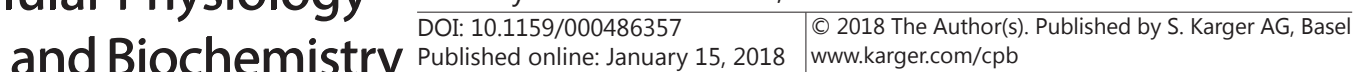

Jiang et al.: : Lncrna Kcnq1ot1 is Involved in the Generation of LQTS

\section{Acknowledgements}

This project was supported by the National Natural Science Foundation of China (Grant No. 81673426 and 81603105), the Foundation for Innovative Research Groups of the National Natural Science Foundation of China (Grant No. 81421063), National Natural Science Foundation of Heilongjiang Province (Grant No. LC2015034). B.Y., Y.B., P.V. and Y.J. participated in research design. Y.J., Y.B., Z.W. and E.Y. wrote or contributed to the writing of the manuscript. Q.C., G.T., L.C. and X.S. performed the western blotting. Q.C. and Y.Q. performed the real-time PCR. Y.J. and A.L. performed primary cell culture and transfection. W.D. and G.L. performed experiments in the mouse model. Y.L. performed patch clamp analysis. H.W. performed data analysis. All authors reviewed the manuscript.

\section{References}

1 Lengfelder E, Hofmann WK, Nowak D: Impact of arsenic trioxide in the treatment of acute promyelocytic leukemia. Leukemia 2012;26:433-442.

- Soignet SL, Maslak P, Wang ZG, Jhanwar S, Calleja E, Dardashti LJ, Corso D, DeBlasio A, Gabrilove J, Scheinberg DA, Pandolfi PP, Warrell RP Jr.: Complete remission after treatment of acute promyelocytic leukemia with arsenic trioxide. N Engl J Med 1998;339:1341-1348.

-3 Soignet SL, Frankel SR, Douer D, Tallman MS, Kantarjian H, Calleja E, Stone RM, Kalaycio M, Scheinberg DA, Steinherz P, Sievers EL, Coutre S, Dahlberg S, Ellison R, Warrell RP, Jr.: United States multicenter study of arsenic trioxide in relapsed acute promyelocytic leukemia. J Clin Oncol 2001;19:3852-3860.

4 Barbey JT, Soignet S: Prolongation of the QT interval and ventricular tachycardia in patients treated with arsenic trioxide for acute promyelocytic leukemia. Ann Intern Med 2001;135:842-843.

$>5$ Barbey JT, Pezzullo JC, Soignet SL: Effect of arsenic trioxide on QT interval in patients with advanced malignancies. J Clin Oncol 2003;21:3609-3615.

6 Lu JT, Kass RS: Recent progress in congenital long QT syndrome. Curr Opin Cardiol 2010;25:216-221.

7 Wang F, Liu J, Hong L, Liang B, Graff C, Yang Y, Christiansen M, Olesen SP, Zhang L, Kanters JK: The phenotype characteristics of type 13 long QT syndrome with mutation in KCNJ5 (Kir3.4-G387R). Heart Rhythm 2013;10:1500-1506.

8 Elvira B, Warsi J, Fezai M, Munoz C, Lang F: SPAK and OSR1 Sensitive Cell Membrane Protein Abundance and Activity of KCNQ1/E1 K+ Channels. Cell Physiol Biochem 2015;37:2032-2042.

-9 Warsi J, Abousaab A, Fezai M, Elvira B, Lang F: Regulation of Voltage Gated K+ Channel KCNE1/KCNQ1 by the Janus Kinase JAK3. Cell Physiol Biochem 2015;37:2476-2485.

10 Matschke V, Piccini I, Schubert J, Wrobel E, Lang F, Matschke J, Amedonu E, Meuth SG, Strunker T, StrutzSeebohm N, Greber B, Scherkenbeck J, Seebohm G: The Natural Plant Product Rottlerin Activates Kv7.1/ KCNE1 Channels. Cell Physiol Biochem 2016;40:1549-1558.

11 Moss AJ, Shimizu W, Wilde AA, Towbin JA, Zareba W, Robinson JL, Qi M, Vincent GM, Ackerman MJ, Kaufman ES, Hofman N, Seth R, Kamakura S, Miyamoto Y, Goldenberg I, Andrews ML, McNitt S: Clinical aspects of type-1 long-QT syndrome by location, coding type, and biophysical function of mutations involving the KCNQ1 gene. Circulation 2007;115:2481-2489.

12 Casimiro MC, Knollmann BC, Ebert SN, Vary JC, Jr., Greene AE, Franz MR, Grinberg A, Huang SP, Pfeifer K: Targeted disruption of the Kcnq1 gene produces a mouse model of Jervell and Lange-Nielsen Syndrome. Proc Natl Acad Sci U S A 2001;98:2526-2531.

13 Veerman CC, Verkerk AO, Blom MT, Klemens CA, Langendijk PNJ, Ginneken ACGV, Wilders R, Tan HL: IKs Blockade Contributes Importantly to Drug-Induced Long QT Syndrome. Circ Arrhythm Electrophysiol 2013;6:1002-1009.

14 Drolet B, Simard C, Roden DM: Unusual effects of a QT-prolonging drug, arsenic trioxide, on cardiac potassium currents. Circulation 2004;109:26-29.

15 Kumarswamy R, Bauters C, Volkmann I, Maury F, Fetisch J, Holzmann A, Lemesle G, de Groote P, Pinet F, Thum T: Circulating long noncoding RNA, LIPCAR, predicts survival in patients with heart failure. Circ Res 2014;114:1569-1575. 


\section{Cellular Physiology Cell Physiol Biochem 2018;45:192-202 \begin{tabular}{ll|l} 
DOI: 10.1159/000486357 & $\begin{array}{l}\text { O 2018 The Author(s). Published by S. Karger AG, Basel } \\
\text { www.karger.com/cpb }\end{array}$
\end{tabular}}

16 Han P, Li W, Lin CH, Yang J, Shang C, Nurnberg ST, Jin KK, Xu W, Lin CY, Lin CJ, Xiong Y, Chien HC, Zhou B, Ashley E, Bernstein D, Chen PS, Chen HS, Quertermous T, Chang CP: A long noncoding RNA protects the heart from pathological hypertrophy. Nature 2014;514:102-106.

17 Grote P, Wittler L, Hendrix D, Koch F, Wahrisch S, Beisaw A, Macura K, Blass G, Kellis M, Werber M, Herrmann BG: The tissue-specific lncRNA Fendrr is an essential regulator of heart and body wall development in the mouse. Dev Cell 2013;24:206-214.

18 Li X, Zhou J, Huang K: Inhibition of the lncRNA Mirt1 Attenuates Acute Myocardial Infarction by Suppressing NF-kappaB Activation. Cell Physiol Biochem 2017;42:1153-1164.

-19 Pandey RR, Mondal T, Mohammad F, Enroth S, Redrup L, Komorowski J, Nagano T, Mancini-Dinardo D, Kanduri C: Kcnq1ot1 antisense noncoding RNA mediates lineage-specific transcriptional silencing through chromatin-level regulation. Mol Cell 2008;32:232-246.

20 Jin X, Jin H, Shi Y, Guo Y, Zhang H: Long Non-Coding RNA KCNQ10T1 Promotes Cataractogenesis via miR214 and Activation of the Caspase-1 Pathway. Cell Physiol Biochem 2017;42:295-305.

21 Li X, Dai Y, Yan S, Shi Y, Han B, Li J, Cha L, Mu J: Down-regulation of lncRNA KCNQ10T1 protects against myocardial ischemia/reperfusion injury following acute myocardial infarction. Biochem Biophys Res Commun 2017;491:1026-1033.

22 Arima T, Kamikihara T, Hayashida T, Kato K, Inoue T, Shirayoshi Y, Oshimura M, Soejima H, Mukai T, Wake N: ZAC, LIT1 (KCNQ10T1) and p57KIP2 (CDKN1C) are in an imprinted gene network that may play a role in Beckwith-Wiedemann syndrome. Nucleic Acids Res 2005;33:2650-2660.

-23 Mitchell GF, Jeron A, Koren G: Measurement of heart rate and Q-T interval in the conscious mouse. Am J Physiol 1998;274:H747-751.

24 Zhang Y, Dong Z, Jin L, Zhang K, Zhao X, Fu J, Gong Y, Sun M, Yang B, Li B: Arsenic trioxide-induced hERG $\mathrm{K}(+)$ channel deficiency can be rescued by matrine and oxymatrine through up-regulating transcription factor Sp1 expression. Biochem Pharmacol 2013;85:59-68.

-25 Li C, Qu X, Xu W, Qu N, Mei L, Liu Y, Wang X, Yu X, Liu Z, Nie D, Liu Y, Yan J, Yang B, Lu Y, Chu W: Arsenic trioxide induces cardiac fibroblast apoptosis in vitro and in vivo by up-regulating TGF-beta1 expression. Toxicol Lett 2013;219:223-230.

-26 Raghu KG, Cherian OL: Characterization of cytotoxicity induced by arsenic trioxide (a potent anti-APL drug) in rat cardiac myocytes. J Trace Elem Med Biol 2009;23:61-68.

27 Zhao XY, Li GY, Liu Y, Chai LM, Chen JX, Zhang Y, Du ZM, Lu YJ, Yang BF: Resveratrol protects against arsenic trioxide-induced cardiotoxicity in vitro and in vivo. Br J Pharmacol 2008;154:105-113.

28 Vausort M, Wagner DR, Devaux Y: Long noncoding RNAs in patients with acute myocardial infarction. Circ Res 2014;115:668-677.

29 Korostowski L, Sedlak N, Engel N: The Kcnq1ot1 long non-coding RNA affects chromatin conformation and expression of Kcnq1, but does not regulate its imprinting in the developing heart. PLoS Genet 2012;8:e1002956.

-30 Kutter C, Watt S, Stefflova K, Wilson MD, Goncalves A, Ponting CP, Odom DT, Marques AC: Rapid turnover of long noncoding RNAs and the evolution of gene expression. PLoS Genet 2012;8:e1002841.

31 Mustafi D, Kevany BM, Bai X, Maeda T, Sears JE, Khalil AM, Palczewski K: Evolutionarily conserved long intergenic non-coding RNAs in the eye. Hum Mol Genet 2013;22:2992-3002.

-32 Cabili MN, Trapnell C, Goff L, Koziol M, Tazon-Vega B, Regev A, Rinn JL: Integrative annotation of human large intergenic noncoding RNAs reveals global properties and specific subclasses. Genes Dev 2011;25:1915-1927.

-33 Chodroff RA, Goodstadt L, Sirey TM, Oliver PL, Davies KE, Green ED, Molnar Z, Ponting CP: Long noncoding RNA genes: conservation of sequence and brain expression among diverse amniotes. Genome Biol 2010;11:R72.

-34 Chen Z, Robbins KM, Wells KD, Rivera RM: Large offspring syndrome: a bovine model for the human loss-ofimprinting overgrowth syndrome Beckwith-Wiedemann. Epigenetics 2013;8:591-601.

35 Higashimoto K, Soejima H, Saito T, Okumura K, Mukai T: Imprinting disruption of the CDKN1C/KCNQ10T1 domain: the molecular mechanisms causing Beckwith-Wiedemann syndrome and cancer. Cytogenet Genome Res 2006;113:306-312. 